\title{
Discussion On Micro-post Training
}

\author{
Chao Tu ${ }^{1, a}$, Jun Liu ${ }^{2, b}$ Zhiping Zhang ${ }^{3, c}$ \\ ${ }^{1}$ Changchun institute of engineering and technology, China \\ ${ }^{2}$ Changchun institute of engineering and technology, China \\ ${ }^{3}$ Changchun institute of engineering and technology, China \\ afdn_198591@163.com, b181525275@qq.com,409956377@qq.com
}

Keywords: Time fragmentation; Localisation; Micro jobs; Online education

\begin{abstract}
With the development and change of social and economic structure, new professions have been emerging and corresponding job training needs have emerged. Under the new conditions, the post training has the characteristics of time fragmentation, location mobility and object diversity, and it is a feasible training mode to decompose the post into several micro posts according to the professional characteristics and conduct the training in the form of breaking up into parts.

With the development and change of social and economic structure, new professions have been emerging and corresponding job training needs have emerged. However, new job training has different characteristics. It is necessary to break the traditional teaching mode and develop new training mode to catch up with The Times.
\end{abstract}

\section{New economic models create new training needs}

The rise of "Internet +" has profoundly changed the original way of economic operation, as well as the employment market. The demand for some old jobs has largely shrunk, while the new business model has created a large number of new jobs. With the comprehensive advancement of intelligent manufacturing and the in-depth development of artificial intelligence in the future, a large number of jobs will be eliminated and some new jobs will be created at the same time. In the change of these positions, some people feel panic about their abilities, while others see opportunities. Only by embracing the new economy and new jobs can we have tomorrow.

Employment transition is accompanied by employment transition, and education transition is accompanied by employment transition. If the enterprise cannot be transformed smoothly, it will eventually go bankrupt; if the person cannot be transformed, he will eventually lose his job; if the school cannot be transformed, he will eventually be eliminated.

In the process of this transformation, colleges and universities should follow the market closely and develop corresponding training models. The traditional training mode, the education of the university emphasizes the specialty, establishes the complete talent training program, has the complete curriculum system. In traditional society, this education model can not only train people's skills, but also education people, laying a solid foundation for their long-term development. However, the disadvantage is that it is not close enough to follow the market changes, and there is a certain lag in professional adjustment and construction.

In the process of economic model change, in addition to opening new majors for the unemployed, the vision should be more focused on the change of employment demand. The continuous updating of working environment and the differentiation and integration of various professions enable everyone to effectively supplement, reserve and update their knowledge and skills continuously during their career, so as to keep up with the pace of social development and meet the needs of posts. Therefore, there is a large number of job transfer in the market, job transfer demand. These people are so busy with their work that they are hard to have a certain block of time to study. They can only use their spare time and fragmented time for learning and training, which is different from the previous new training needs. 


\section{New training needs spawn micro-jobs}

\section{Features of new demand}

Time fragmentation.

The trainees may be in a busy job every day, dealing with both intense work and trivial family matters, and their learning time cannot be fixed. To fully tap the learning time of such personnel, to maximize the potential of individual learning. The study time can be the commute time, the work time, the break time, the various waiting in the queue time. As long as there is a gap, make full use of it.

The locations are moving.

Trainees may occasionally have time to study in a designated place, but more often the place is no longer fixed. They can learn at work, in transport, on business trips and at home. All in all, the place of study is not just a fixed institution.

Object diversity.

The target may come from all walks of life, have relevant professional or post personage to undertake transfer job study, also may be the layman enters a brand-new domain. The learning of relevant professionals requires courses to make them know the relationship between their original position and their current position, and then quickly transition to the new position. For the layman, some courses are needed to introduce them, and then some courses are used for systematic training.

\section{Micro position is an effective way to meet new demands}

Traditional vocational school education, the training time is fixed, the training place is limited, the training object is single, and does not meet the new requirements. The time fragmentation and location mobility of the subject make the training course short and concise, and the course is too long to complete the study systematically.

From the perspective of work post, the task of the post needs to be further decomposed and refined to form a modular and building block job division, which is convenient for the rapid completion of post transformation. It is necessary to combine the post task demand with the talent training path, cut and decompose the sub-function modules that cannot be divided as much as possible according to the post function, and decompose the minimum unit of the post task, which is called micro post. Set micro courses according to the post and train people according to micro courses. After the training is qualified, the post qualification certificate will be issued and the post certificate will be issued.

The training object will continue to learn certain micro post skills for a period of time, and then practice under certain conditions. After truly mastering the knowledge and skills of micro post, it will learn the next micro post. When the training object has mastered all the micro post skills, it can acquire the post capacity of the profession and enter the post for work.

The new training needs can be met by resolving the jobs corresponding to the job into micro positions and then establishing the training mode suitable for micro positions.

\section{Micro post needs the reform of teaching mode}

\section{Facing the emblem post, online education must be vigorously developed}

As the subject needs to complete daily work, the time for off-job training should be reduced as far as possible. Anyone who can carry out education online teaching with the help of online teaching resources should be able to do so. Those who cannot conduct education online should be able to complete the last kilometer of training by the school.

Vocational education colleges and universities should build resources according to their own strong technical reserve, faculty, and hardware and software conditions. Relying on the online learning room, we develop online courses, micro courses and moocs. Colleges and universities should lower their stature, fully participate in market competition, develop mobile app software suitable for fragmented learning, and conduct online learning guidance, process assessment, online assessment, qualification certification, etc. 


\section{For micro positions, colleges and universities should focus on training objects}

Online education can not solve the problem of skill training, the final mile of the problem must be solved by the university. Now in the teaching management, the school is in the main position, the training object revolves around the school, learning content, time, place is not flexible enough. In the future, colleges and universities should focus on customers, and interact with each other on course selection, time and place, so as to meet the requirements of micro-post training for learning with fragmented time.

Also can establish order type training with unit of choose and employ persons, according to the working characteristic of groom personnel, when working task is not nervous, can undertake to the school centralize training. The training required before and during the emergency tasks such as the business transformation of the employer shall be provided by the personnel dispatched by the institution to participate in the training.

\section{References}

[1] Gu Congbiao,Tang Qingzhao, Hu Gang. Influence of precision-guided weapons on modern war [J]. Air navigation missile, 2006.04

[2] Lu Jixuan. Characteristics and restraining factors of psychological confrontation in modern war [J]. Research on military political and industrial theory,2016.08

[3] Zhang Guofeng. Russian military (2014-2016) under the background of profound changes in international strategic pattern $[\mathrm{J}], 2017.05$

[4] Tang Zaijiang, Wang Jingye, Shu Xiuli. Research on single-tank combat effectiveness evaluation based on equipment combat simulation method [C].2004 academic communication conference on system simulation technology and its application,2004.08

[5] Zhu Minjie, Wang Jingye, Li Guanghui. Integrated simulation experimental framework for comparison of operational efficiency of main battle equipment [J]. Journal of system simulation, 2010.11

[6] Qin Shumin and Cao Hui. Development trend analysis of fire control viewing system of tank armored vehicles [J]. Fire control and command control,2009.09 